\title{
Plastic accumulation during COVID-19: call for another pandemic; bioplastic a step towards this challenge?
}

\author{
Mahak Mittal $^{1} \cdot$ Divya Mittal $^{2} \cdot$ Neeraj K. Aggarwal $^{1}$
}

Received: 21 September 2021 / Accepted: 23 November 2021 / Published online: 13 January 2022

(c) The Author(s), under exclusive licence to Springer-Verlag GmbH Germany, part of Springer Nature 2021

\begin{abstract}
Plastic pollution has become a serious transboundary challenge to nature and human health, with estimation of reports published - predicting a twofold increase in plastic waste by 2030. However, due to the COVID-19 pandemic, the excessive use of single-use plastics (including face masks, gloves and personal protective equipment) would possibly exacerbate such forecasts. The transition towards eco-friendly alternatives like bio-based plastics and new emerging sustainable technologies would be vital to deal with future pandemics, even though the use or consumption of plastics has greatly enhanced our quality of life; it is however critical to move towards bioplastics. We cannot deny the fact that bioplastics have some challenges and shortcomings, but still, it is an ideal option for opt. The circular economy is the need of the hour for waste management. Along with all these practices, individual accountability, corporate intervention and government policy are also needed to prevent us from moving from one crisis to the next. Only through cumulative efforts, we will be able to cope up with this problem. This article collected scattered information and data about accumulation of plastic during COVID-19 worldwide. Additionally, this paper illustrates the substitution of petroleum-based plastics with bio-based plastics. Different aspects are discussed, ranging from advantages to challenges in the way of bioplastics.
\end{abstract}

Keywords COVID-19 · Plastic waste · Bioplastics · Polyhydroxyalkanoate · Vaccination · Circular economy

\section{Introduction}

Plastic is indispensable in almost each and every sector and therefore cannot be underestimated, since it is used in electronics, health care, textile, construction, transportation, etc. The utility of plastic is diverse because of its versatile quality, durability, low cost, high strength, less resistance to corrosion and other good mechanical properties (Silva et al. 2020a). Especially, the health care sector has been greatly changed by the advances made with plastics. With the improvements, particularly surgical gloves, syringes, insulin pens, inflatable splits, and masks for one-time use,

Responsible Editor: Lotfi Aleya

Neeraj K. Aggarwal

nkumar@kuk.ac.in

1 Department of Microbiology, Kurukshetra University, Kurukshetra 136119, Haryana, India

2 Maharishi Markandeshwar (Deemed To Be University), Mullana 133207, Haryana, India the medical industry has become more cost-effective, simpler, and safer (Anderson et al. 2021).

As we all know, since Dec. 2019, the population of the world was tremendously affected by a pandemic that originated from a novel coronavirus (SARS-CoV-2) causing a serious respiratory disease known as COVID-19 (WHO 2020b). Transmission of this syndrome is allied with high contagiousness, i.e. direct personal contact or indirect contact with contaminated surfaces, waste, oral transmission, airborne/through the respiratory droplet, etc. (Dietz et al. 2020). Several precautionary steps have been adopted by governments around the world to flatten the disease curve, for instances, partial or total lockdown, limits on social interactions, less movement of passengers, reduction in economic activities, etc. (Tobas 2020). The use of personal protective equipment (PPE) has increased dramatically during this widespread COVID-19 infection. Individuals are under pressure to protect themselves by wearing gloves, masks, and using sanitiser since this disease is unavoidable and highly infectious (Kleme et al. 2020a). Moreover, frontline healthcare workers, medical professionals, and other medical staff use a lot of plastic protective items (Manigandan et al. 2020). 
Public preference for disposable packaging has moved in the direction of plastics over all other alternatives (Scaraboto et al. 2019). Furthermore, national curfews and home-quarantine orders have caused a greater reliance on online food and other essential grocery delivery, possibly contributing to an increase in plastic packaging waste (Singh 2020; Staub 2020). As the world begins to recover from this pandemic, we may recognise that our raised reliance on plastics at the detriment of our environment has resulted in a new plastic waste epidemic with which we have been grappling. This massive use of petroleum-based plastics continues to accumulate in our environment. We know that the nature of this plastic is non-biodegradable; it creates a lot of problems for our environment. So there is an urgent need to look for some alternatives to deal with these petroleum-based plastics.

This paper illustrates, how urgency and chaos created by COVID-19 have led to the tremendous use of petroleumbased plastics. Various segments of health industry which are responsible for generating plastic waste (particularly during a pandemic) are discussed, like mask usage, PPE kits, diagnostic test, and vaccination. This also reviews the other sectors primarily contributing to pilling up the plastic waste such as packaging, behavioural changes among people, and consumption habits due to fear of transmission. It also identifies the sustainable approaches to deal with this waste like circular economy, use of bioplastics with particular focus on PHA along with its diverse applications and challenges. The article, in the end, sheds light on the possible mitigation and solutions to overcome the shortcomings.

\section{An overview of SARS-COVID-19}

COVID-19 is regarded as the most serious health pandemic of the twenty-first century, which has challenged the entire humankind. It is a zoonotic disease disseminated worldwide by a beta group of coronaviruses named severe acute respiratory syndrome coronavirus 2 (SARS-COV-2) (Mackenzie and Smith 2020). People are more susceptible to viral infection due to exceptionally high rate of transmission. Fever, cough, fatigue, muscle discomfort, dyspnoea, pneumonia, and low leukocyte counts are all common signs of COVID-19. Sore throat, diarrhoea, conjunctivitis, headache, skin rashes, or discoloration of fingers or toes are some of the less common symptoms ( $\mathrm{Li}$ et al. 2020). COVID-19 is more likely to affect elder people and those with pre-existing medical conditions like diabetes, heart problems, and severe asthma. Patients of COVID-19 having chronic type-2 asthma face a significant risk, as the condition and associated morbidities may worsen (Ghosh et al. 2021). Literature suggested that the impact of COVID-19 has not been only restricted to the respiratory system but it also affects the CNS through neuronal transport (Nagu et al. 2021). Studies reveal that approximately $36.4 \%$ of COVID- 19 patients develop neurological disorders (Wu et al. 2020). The first incidence of viral encephalitis was reported on March 4, 2020, in Beijing Ditan Hospital, demonstrating the ability of SARS-CoV-2 to enter the central nervous system (Xiang et al. 2020a, b). The pandemic of the severe acute respiratory syndrome coronavirus has prompted global effort to find urgent treatment remedies to reduce the mankind damage caused by COVID-19 (Negrut et al. 2021). As per WHO, there have been 251,788,329 confirmed cases of COVID-19, including 5,077,907 deaths (data updated on $12^{\text {th }}$ November 2021). A total of $7,160,396,495$ vaccine doses have been administered.

\section{Lockdown: an important step taken by Governments}

Lockdown, the main preventive measure to reduce the transmission of COVID-19, was adopted by governments of different countries. As a coin always has two sides, similarly, this practice put both positive and negative impacts parallelly given in Table 1 .

At first sight, the COVID-19 pandemic appears to be indirectly contributing to the UN 2030 Sustainable Development Goals (SDGs) through improving overall city health and safety by reducing emissions of greenhouse gases (GHG), air pollution, noise pollution (due to a reduction in transportation), land and wildlife disturbance, etc. However, consequences were also there like increased use of single-use plastics and ecological risk due to different disinfectants (Silva et al. 2020b).

\section{Impact of COVID-19 on plastic waste}

The COVID-19 has significantly increased the amount of plastic used regularly. It is critical to recognise that, following the emergence of the COVID-19 pandemic, we are living in a new and unknown reality. With the temporary
Table 1 Both positive and negative impacts of lockdown

\begin{tabular}{ll}
\hline Positive impact of lockdown & Negative impact of lockdown \\
\hline - Improved outdoor air quality & • Decreased indoor air quality \\
- Reduction in noise pollution & $\bullet$ Increased medical waste generation \\
- Reduction in emission of GHGs & $\bullet$ - Increased level of plastic \\
- Decrease in deforestation & $\bullet$ Increased ecological risk to ecosystems due to use of disinfectants \\
\hline
\end{tabular}


closing of shops and restaurants during lockdowns and government-imposed 'stay-at-home' orders, the current situation has changed our living standards and habits, causing concern in our waste generation routines (Bengali 2020). In addition, the face of transmission anxiety has modified our behavioural habits, such as the widespread use of personal protective equipment (PPE), extensive demand for plastic-packaged food or other groceries, and the usage of disposable utensils, for both convenience and reassurance (Tenenbaum 2020).

The health industry is one of the major contributors to piling up plastic waste. Initially, the focus was mostly on the management of the disease, but over the last few months, everybody has taken and adopted preventive steps. The key components to follow as a preventive measure are wearing face masks and regular hand disinfection (Kleme et al. 2020b). Plastic is used in the manufacture of both face masks and hand sanitiser bottles. Polypropylene (PP), which is difficult to recycle, is a popular plastic used in face masks.

The World Health Organization suggested the mandatory use of PPEs in the hospitals for safety and projected that the world would need 89 million face masks, 76 million glove pairs, and 1.6 million pairs of protective goggles in a month to meet rising global demand (WHO 2020a). At the peak of the pandemic, Wuhan (a city of China) alone has generated approximately 240 tons of medical waste in a day, nearly 6 times more than before the outbreak (Singh et al. 2020). The COVID-19 pandemic is causing an additional 309 tonnes of healthcare waste every day in Manila, a 14-million-people city (ADB 2020). The pandemic has prompted a rapid increase in the production of much-needed PPEs or other plastic items in the United States and other parts of the world (Picheta, 2020). These development patterns appear to be reversing the momentum of global policies to eliminate single-use plastics that have been in place for years (Eriksen et al. 2014). Face masks have been reported to be accumulating on Hong Kong beaches and nature trails (Reuters 2020). The pandemic's staggering economic costs are exacerbated by the effects of single-use plastic items (Beaumont et al. 2019; Wright and Kelly 2017).

\section{Plastic waste due to the extensive use of face mask}

Because of the current pandemic, wearing a mask has become a necessity for all human life. To combat the global pandemic, different mask types available like N95, surgical, and fabric or cloth masks are being used. According to a study conducted by the World Health Organization (WHO), approximately 89 million medical masks are needed in the United States to deal with the COVID-19 outbreak, which is expected to last for some time (Xiang et al. 2020a, b). Furthermore, the plastic innovation hub estimates that the mask's annual domestic demand in the United Kingdom is about 24.37 billion per year (Liebsch 2020). China has raised its daily production of masks to 14.8 million as of Feb. 2020 (Fadare and Okoffo 2020). The use of masks is rapidly growing, which means more masks are being produced and more energy is being consumed. According to a report, the manufacture of a mask takes around 10-30 W of energy and emits $59 \mathrm{~g} \mathrm{CO}_{2}$-eq of greenhouse gas into the atmosphere (Selvaranjan et al., 2021). Furthermore, the increasing use of face masks contributes to medical waste and landfill as well. Majority of these mask wastes have either polyethylene or polypropylene, polyurethane, polystyrene, polyacrylonitrile, and polycarbonate which add plastic waste or cause microplastic pollution to the environment (Abbasi et al. 2020). In European Unit (EU), during the first half of the pandemic, the import of gloves and masks became more than doubled. According to European Environment Agency (EEA), about 0.75 face masks per individual per day and around 170,000 additional tonnes of masks were imported only in the EU at that time, which leads to huge emissions of greenhouse gases and various types of pollutants (EEA 2021). This indicates that the current pandemic is increasing pollution in the environment and has a detrimental effect on human and animal health. According to a study, surgical masks and N95 masks contain $4.5 \mathrm{~g}$ and $9 \mathrm{~g}$ of polypropylene, respectively. Based on mask wastes generated per week, the total max. and mini. amount of polypropylene produced per week from various countries is determined in Fig. 1. This demonstrates that the COVID-19 pandemic would influence not only health and the economy, but also the environment's long-term viability.

\section{Plastic waste due to diagnosis of COVID-19}

This is how masks incredibly piling the plastic in our environment. Furthermore, the diagnosis of the virus is also using plastics. Whether a person is infected or not can only be determined through the genome of the virus. Though antigen-antibody test can also be done (Beeching et al. 2020).

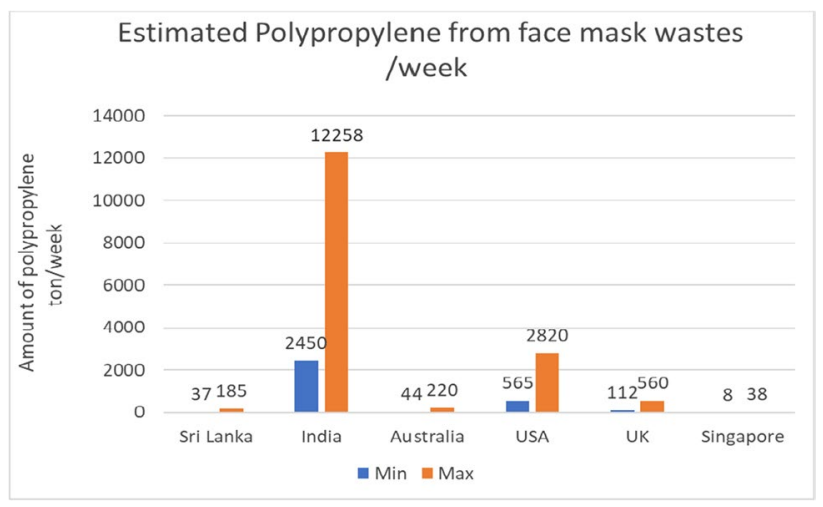

Fig. 1 Estimation of the total amount of polypropylene from face mask waste per week 
But gene identification is an accurate and most complex test where genes of the virus are identified. Therefore, this procedure is currently used to confirm the COVID cases. For this, a swab is required to get a sample either from the nose or lungs which are immediately poured into a plastic tube having chemical preservatives. Afterward, the taken sample is extracted and analysed through RT-PCR. This technique uses different supplies, the majority of which are singleuse plastics (Tang et al. 2020). A study evidenced that for a single sample, the RT-PCR generates $37.27 \mathrm{~g}$ of plastic residue. Until August 2020, all COVID-19 patients tested with RT-PCR have produced 15,439.59 tonnes of plastic residue around the world (Celis et al. 2021).

\section{Vaccination drive leading generation of plastic waste}

Following the COVID-19 pandemic's faster, vaccine development paradigm and the global expansion of immunisation programmes, a significant increase in the plastic residual waste from vaccine containers is expected. The burden would be borne disproportionately by developing countries, which already have limited resources for waste management, resulting in negative short- and long-term environmental and financial consequences (Phadke et al. 2021). Governments all around the world are scrambling to vaccinate as many people as possible to keep the pandemic under control (Fast Company 2021). First, there was the personal protective equipment (PPE) kits, included masks, gowns, gloves, and other items used by healthcare and frontline workers, as well as diagnostic kits for testing. But now, there are thousands upon thousands of syringes supplied for immunisation campaigns. The use of syringes is rapidly increasing (The Print 2021). According to one estimate from Onsite Waste Technologies, an American company that specialises in medical waste management, the needles from the number of vaccine doses needed to inoculate the entire US population are roughly 66 crore that would be enough to wrap around the Earth 1.8 times. To put things in perspective, India's population (including minors who are currently not eligible for vaccination) exceeds that of the United States by about 100 million people. According to another estimate by the Association of Indian Medical Device Industry (AIMED), the world would require 800 billion to 1,000 billion syringes to vaccinate $60 \%$ of the population, which is the approximate threshold for herd immunity. They predicted that inoculating $60 \%$ of India's approximately 135 million people will require at least 150 million syringes. The COVAX Facility aims to deliver at least 1.8 billion doses of COVID-19 vaccine to 92 low- and middle-income countries by the end of year 2021 . All those single-use syringes and needles, if laid end-to-end, could round the globe numerous times (The Print 2021).

\section{Other factors - including people behavioural change thus lead to packaging waste}

Plastic stagnation has been worsened not just by the medical industry, but also by food packaging (Hahladakis et al. 2018). After the government imposed a complete lockdown to slow the spread of COVID-19, everyone's everyday schedule was disrupted and changed drastically as a result of being at home for $24 \mathrm{~h}$. This increased the number of online purchases, which would not have been possible without packaging. In this pandemic, an immense amount of plastic has surged in the form of box covers (Anderson et al. 2021). Figure 2 shows the plastic waste produced due to different activities during a pandemic. COVID-19 has heightened public anxiety about the disease's ease of transmission. For the sake of protection, people have become more conscientious about their hygiene as well as the hygiene of their food and groceries. This pandemic has totally changed people's minds about their health and their families, resulting in food and other essential items being delivered in a tidy and safe manner. People have switched to online purchases and single-use plastics as their understanding of reusable plastic items, such as tea cups, food plates, food containers, and packaging covers, has changed due to their infectious conditions. Furthermore, social distancing has driven people to buy processed goods and food from their homes. Online shopping and takeout have resulted in a large number of items being delivered to every home (Anderson et al. 2021). Thailand produces approximately 6,300 tonnes of household waste per day as a result of social distancing and isolation policies, including a $15 \%$ increase in plastic waste, almost seven times more than before the pandemic (Wipatayotin, 2020). For example, according to a survey conducted by The Los Angeles Times in Singapore, the island city, 5.7 state's million residents discarded 1,470 tonnes of extra plastic waste from food delivery and takeout packaging alone. According to report, due to COVID-19,

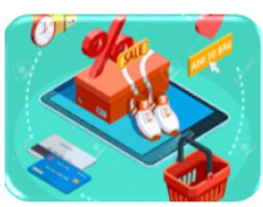

Surge in online shopping

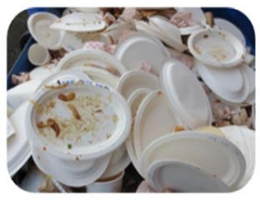

Disposable food utensils

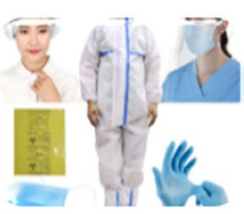

PPE kits

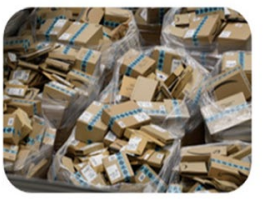

Packaging waste

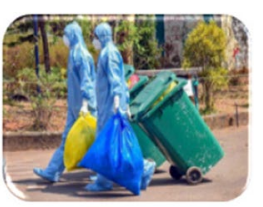

Other biomedical waste

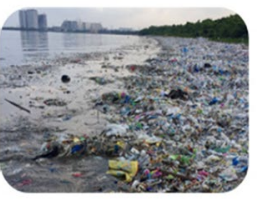

Piling in oceans
Fig. 2 Plastic waste from diverse activities during pandemic 
online purchases for food and daily necessities increased by 92.5\% and $44.5 \%$ in South Korea, respectively, and online shopping rates increased by $12-57 \%$ in India, China, and Italy (Anderson et al. 2021). What began as a health issue quickly morphed into an economic, social, and, most importantly, environmental threat. Therefore, corrective steps should be taken until it is too late to mitigate this unwanted and unavoidable global issue.

\section{Adverse effects of plastics on human health and the environment}

Since most protective equipment is made of plastic, plastic plays an important role in the battle against the COVID19 pandemic. However, certain properties of plastic, like non-biodegradability, lower melting point, and limited service life, are disadvantages that may have negative health, environmental, and animal health consequences. Plastics are mainly composed of crude oil and natural gas through the process of addition and condensation polymerisation (Pan et al. 2020), for example, reaction of organic diacids with alcohols to form polyesters like polyethylene terephthalate (PET). PET is formed by the condensation polymerisation of terephthalic acid with ethylene glycol with the elimination of water molecules. This mechanism is known as step growth polymerisation, while polymers such as polypropylene and polyethylene are formed by the simple linking of monomeric units: propylene and ethylene respectively without the generation of any other products. This is known as chain growth polymerisation (Saxon et al. 2020). Plastics used in area of packaging intended for human convenience are hazardous as they contain additives (the toxic compounds used to improve properties of plastic, e.g. colorants, fillers, and plasticisers). This poses a threat to the health of humans and as well as animals (Khoo et al. 2021). Recent plastics research has focused on human health and environmental issues, such as the prevalence of endocrine-disrupting compounds in plastics and the long-term contamination of the atmosphere by plastic waste (North and Halden 2013). The majority of plastic waste is non-biodegradable, with a lifespan ranging from less than a year to more than 50 years (Potrykus et al. 2021). Furthermore, when plastic waste litter is exposed to UV radiation, photo- and thermo-oxidative degradation occurs, resulting in secondary microplastics or microbeads with a size of 10-500 $\mathrm{m}$ (Andrady 2011). These have negative consequences for marine species like fish, prawns, and crabs, which can accumulate ingested microplastic. Microplastics contain a variety of hazardous chemicals, including organic pollutants such as pesticides, flame retardants, and PCBs additives, which bioaccumulate or be ingested by humans (Li et al. 2016a, b).

\section{Different disposal approaches used for plastic waste}

Landfilling, incineration, recycling, and biodegradation are four options for plastic disposal. According to the Ellen McArthur Foundation, $16 \%$ of global plastic waste is manually recycled, $25 \%$ is incinerated, and $40 \%$ is disposed of in sanitary or non-sanitary landfills. The remaining $19 \%$ of plastic is discarded in the atmosphere, clogging water, and drainage systems. Every type of plastic is discarded in landfills and incinerators, but the most important thing is that it takes up the least amount of space possible, and the energy and chemicals present in the plastic items are lost as a result of the disposal method (Prata et al. 2020). Any type of plastic, regardless of its type or impurity level, can be burned using the incineration process (WHO 2020c). Overall, this is the most appropriate method for disposing of COVID infectious and infected plastic waste. Even the World Health Organization has recommended incineration for infectious plastic waste. However, during the incineration, toxic gases are released, which can have negative health and environmental consequences. Hazardous gases, like dioxins and furans, are also emitted by the inefficient and poorly managed incineration system. Recycling is the third process. The majority of plastics can be recycled into new products. Mechanical recycling has several limitations, including polymer cross-contamination, inorganic impurities, and the use of additives. Furthermore, in contrast to the recycling process, collecting and sorting plastic waste is the most difficult aspect, whereas chemical recycling is a critical opportunity to reduce terrestrial as well as marine pollution. This also enables the implementation of the circular economy. Pyrolysis and gasification are the two main chemical processes because of their durability and economics (Dogu et al. 2021). Single-stream plastics, such as PET (polyethylene terephthalate), can be recycled with fewer impurities, but multi-layered plastics and single-use plastics, like film and foam, are more difficult to recycle due to their poor integral structure, high preprocessing costs, and technical limitations. Poly (methyl methacrylate) (PMMA), also known as acrylic or plexiglass. Recycling of PMMA can be done by thermal or non-catalytic method, which results in degradation and yield mixture of different monomeric units (Moens et al. 2020). Thermal degradation normally changes the molecular weight of the polymer. PMMA waste contains various additives and backbone which is commonly made up of copolymer instead of homopolymer (which is present in pure PMMA). There are different methods of degradation. For instance, the unrestricted depolymerisation of the MMA copolymer is one of the options. This means that the non-MMA monomer unit has no effect on the degradation 
mechanism, and therefore, chains unwind without difficulty. This type of behaviour can be seen when the comonomer, which is likewise a methacrylate lacking an ester group, decomposes during the thermal degradation process (Moens et al. 2020). Another major issue is a shortage of manpower. People are afraid to gather waste and be in the process of COVID-19 plastic waste disposal due to the risk of infection transmission during COVID. Because of this practical challenge, this method of plastic disposal is ineffective and underutilised. The best approach is to manufacture biodegradable plastic products, but since they take a long time to degrade, the plastic accumulation increases. The similarity in appearance of biodegradable and nonbiodegradable goods can often cause the process of sorting out the plastic items to be delayed. Due to logistical challenges in recycling practises and the general public's carelessness, there is an abundance of landfill and plastic floating in the oceans. According to a survey conducted by a Hong Kong-based NGO, 300 million tonnes of plastic are manufactured worldwide each year. Eight million tonnes of plastic waste were poured into the oceans as a result of this. This ratio assumes that one truckload of plastic waste is dumped into the sea every minute. This deafening endangers underwater biodiversity and devastates the marine environment. Furthermore, dumped plastics are toxic, and when eaten by sea animals, they damage them as well as humans who eat poisonous fish and other sea creatures. By 2025, the volume of plastic in the ocean would be greater than the weight of the fish in it if the current rate of dumping continues. Aside from that, the volume of garbage in landfills has risen as a result of the pandemic. Coronavirus plastic is expected to clog landfills and float in the seas in $75 \%$ of cases. Since the environment and human life are in danger, the government must expend a significant amount of money, resulting in an unsustainable reduction in the budget allocated to other essential public health programmes (Rhodes 2018). According to the UN environmental programme, after COVID-19, the cost of environmental corrective measures will hit 40 USD billion per year, which is lower than the previous year (European Commission 2018). Plastic pollution has a detrimental effect on fisheries, marine transportation, and tourism. Because of the current unfavourable pandemic situation, careful and proper management of plastic waste is required.

\section{Bioplastics}

The growing threat of plastic waste as a result of the pandemic is an undeniable fact that necessitates mitigation strategies. The word 'bioplastic' refers to a variety of materials:
1. Plastics that are biobased but not biodegradable;

2. Plastics that are biodegradable but not biobased;

3 . and the plastics that are both biodegradable and biobased (Philp et al. 2013; Sinan 2020).

All these categories are depicted in Fig. 3.

The word 'biodegradable plastic' refers to a plastic that is both bioderived and biodegradable in this article, while 'bioplastic' refers to any plastic made from biomass. The ASTM D6400 (United States), EN13432 (Europe), and ISO17088 (International) standards control biodegradability. True biodegradable plastics, according to these guidelines, degrade due to the natural activity of microbes like bacteria, fungi, and algae. $\mathrm{CO}_{2}$, methane, water, and biomass should be the end products, with no ecotoxic effects or residual by-products. A comparison of petroleum-based plastics and bioplastics is given in Table 2 (Naser et al. 2021). Bioplastics have several advantages over petroleum-based plastics due to biodegradability; however, the production cost is high (Leal Filho et al. 2021).

The development of biodegradable plastics (BPs) made from renewable feedstock is currently a hot topic. Renewable biomass or raw materials like cellulose, lignin, starch, and bioethanol are commonly used to make BPs. Polylactic acid (PLA), polyhydroxyalkanoate (PHA), polyhydroxybutyrate (PHB), and polyhydroxybutyrate valerate (PHBV) are the most popular biodegradable and commercially available biopolymers in the market today. Biodegradation of BPs is possible without any negative consequences (Haider et al. 2019).

\section{Bioplastics and India}

In India, the bioplastics industry is still in its infancy. In India, only a few companies are involved in the bioplastics

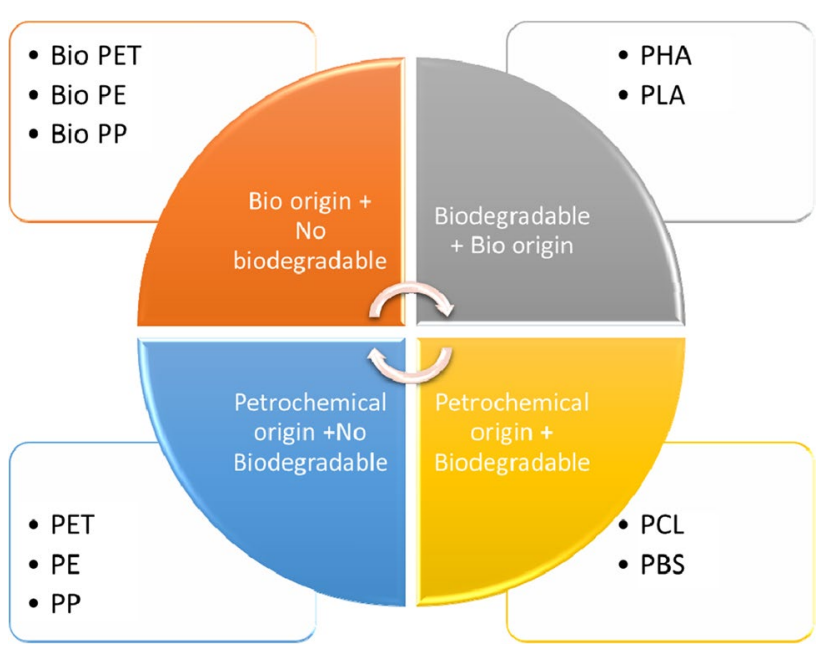

Fig. 3 Different categories of bioplastics 
Table 2 Comparison of petroleum-based plastics and bioplastics

\begin{tabular}{ll}
\hline Conventional plastics & Bioplastics \\
\hline - Mainly chemical based & $\bullet$ Microbial or natural origin \\
- Emission of greenhouse gases & $\bullet$ Less or no emission of greenhouse gases \\
- Non-biodegradable therefore harmful & $\bullet$ Biodegradable therefore harmless \\
- Difficult recycling & $\bullet$ Easy recycling \\
- Production cost is low & $\bullet$ Production cost is high \\
\hline
\end{tabular}

industry. Environmental awareness projects, quick access to feedstock, and government funding are all helping bioplastics manufacturers thrive in India. More initiative is required in the areas of manufacturing, raw materials, and technology growth. An initial move in introducing this transition is to raise environmental awareness and promote the long-term benefits of bio-plastics. The National Green Tribunal's (state-level committee) has given the government until August 31, 2019, to enact the plastic ban. Scientists are working on the development of bioplastics all over India. Recently IIT Guwahati came up with an improvement in commercial production of bioplastics (Kalita 2019). India's first biotechnology company for biodegradable products is Biogreen. Bioplastics are already being produced in India by Truegreen, Plastobags, Ecolife, and Envigreen (Biogreen 2017). Many technological breakthroughs have enhanced the Indian Bioplastics market, which has seen significant growth. It is up to each person to and their use of traditional plastics as much as possible in their everyday lives (India Bioplastics Market 2019).

\section{Substitution potential of bioplastics}

While current substitution levels are low, biodegradable polymers have the potential to replace the majority of different petroleum-based polymers currently in use, as shown in Table 3 (Shen et al. 2009). Extensive research has been done to study the technological replacement potential of biobased plastics to replace their petrochemical equivalents. As of 2007 , reported that biobased plastics could replace conventional plastics at the rate of $94 \%$, with $31 \%$ of that coming from biodegradable plastics and $63 \%$ coming from biobased but not biodegradable plastics. The substitutional potential of bioplastics over conventional plastics concerning cost is well documented. Figure 4 shows the average price of different polymers (Shen et al. 2009). Due to economic considerations, difficulty in a quick scaleup, difficulty in assuring availability of renewable (biobased) feedstocks, and the plastics industry's sluggish acceptance of new plastics, it is unlikely that this potential will be realised in the short-tomedium term. (Shen et al. 2009). Due to the slow rate of substitution, any environmental trade-offs, such as a reduction in non-renewable energy usage, will take more than two decades to realise at a macro-scale. They do, however, point out that an advantage of this incremental change may be the prevention of technical lock-in and the opportunity to ensure that the most environmentally friendly, cost-effective processes are implemented (Dilkes-Hoffman et al. 2019).

Starch, polylactic acid (PLA), and polyhydroxyalkanoate (PHA), these three biopolymers however are tempting for substituting petroleum-based plastics. Table 3 shows clearly the substitution potential. While some can replace partially, some can fully (Shen et al. 2009). For instance, starch is considered one of the best renewable biopolymers, because of its biodegradable nature, huge abundance, and lower production cost (Peelman et al. 2013). Currently, starch has many applications in diverse sectors like medicine, food, agriculture, and packaging (Shafqat et al. 2020; Liew and Khor 2015). Similarly, PLA is also regarded as major bio polyester, particularly known for medical and packaging applications (Vert et al. 1995). Several companies are producing different types of PLA products (Sinclair 1996; Lunt 1998). Its tunability and huge abundance make it a potent alternative to petroleum-based plastics for packaging applications like bottles, treys, and cups (Auras et al. 2004). A study reported that the cost of PLA is the lowest of all biopolymers (Sin et al. 2013). The third is polyhydroxyalkanoate (PHA), synthesised by microbes intracellularly as reserved food material. PHA too can replace a variety of conventional plastics. It has applications in medical, packaging, agriculture, etc. (Li et al. 2016a, b).
Table 3 Substitution potential of bioplastics with different types of conventional plastics

\begin{tabular}{llllllllll}
\hline & PVC & HDPE & LDPE & PP & PS & PA & PET & PBT & PC \\
\hline Starch blends & ++ & ++ & ++ & + & + & $+/-$ & + & + & - \\
PLA & - & + & + & + & - & + & + & - & - \\
PHA & + & + & + & + & $+/-$ & - & $+/-$ & $+/-$ & - \\
\hline
\end{tabular}

++ , full substitution; - , no substitution; + , partial substitution; $P V C$, polyvinylchloride; $H D P E$, highdensity polyethylene; $L D P E$, low-density polyethylene; $P P$, polypropylene; $P S$, polystyrene; $P A$, polyamide; $P E T$, polyethylene terephthalate; $P B T$, polybutylene terephthalate; $P C$, polycarbonate 


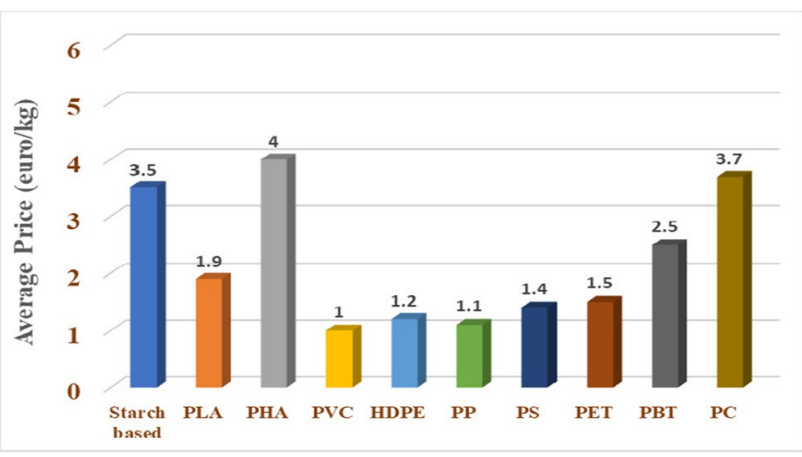

Fig. 4 Average prices of different polymers in year 2009

According to the study of the European bioplastics nova institute, the packaging sector holds a major proportion of bioplastics production over all other different sectors including electronics, agriculture, textiles, and construction as represented in Fig. 5.

\section{Challenges for bioplastics}

The key feedstocks, water footprint, land use, and minimal infrastructure all pose challenges for bioplastics. However, incorporating processing in a biorefinery and using by-products and waste flows as raw materials will greatly reduce the ecological footprint (Tsang et al. 2019; Ummalyma et al. 2020; Ivanov and Christopher 2016; Zhang et al. 2018). Due to their polysaccharides and lignin, recent studies have shown that wood and other lignocellulosic residues from agroforestry will be more sustainable alternatives (Tedeschi et al. 2020). For example, producing PHA from a variety of biomass sources, municipal wastewater, $\mathrm{CO}_{2}$, and $\mathrm{CH}_{4}$ has additional advantages for the long-term growth of bioplastics (Drre and Eikmanns 2015; Ampelli et al. 2015; Crumbley and Gonzalez 2018).

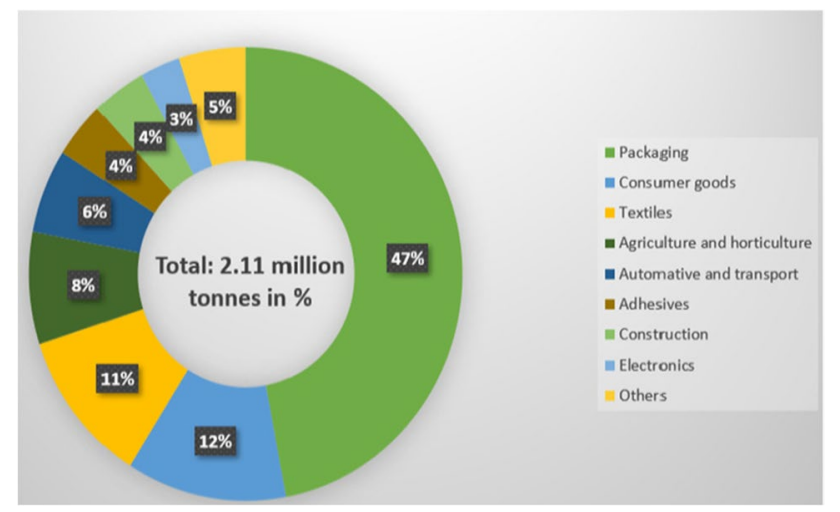

Fig. 5 Global production capacities of bioplastics in 2020 (by market segment) (European bioplastics, nova institute 2020)
Other than these, several challenges are also there due to the lack of awareness and information among people, as represented in Fig. 6 (Leal Filho et al. 2021).

\section{Circular economy: a perspective for waste management during COVID-19 pandemic}

This unforeseen circumstance has prompted countries to adopt an approach of linear economy for waste management, which entails harvesting resources to manufacture new goods, with the majority of these products ending up in landfills or the natural environment (Hahladakis et al. 2020; Payne et al. 2019). Before the COVID-19 era, approximately two billion people in the world lacked facilities for waste collection, and three billion lacked proper disposal systems (Wilson et al. 2015). As a result, it is unsurprising that the linear economy has contributed significantly to the rise in the aforementioned plastic waste crisis. It is critical to shift and take steps toward more possible sustainability models, such as a circular economy, to resolve the stated environmental problems surrounding plastic and medical wastes. A circular economy is an ideal alternative to a conventional linear economy that includes production, usage, and disposal. This approach aims to minimise resource consumption (reduce) and reuse existing products for as long as possible (reuse) or accept waste as new sources (recycle or recover) by using recycling and recovery facilities. Three main components of this scheme are shown in Fig. 7.

During the period of lockdown, however, the majority of material recovery facilities were shut down due to concerns from formal, informal, and local authorities about the possibility of coronavirus spreading among waste handlers. As a result, having adequate waste facilities (including collection, transport, and disposal) while taking into account minimal health hazards has created an issue and challenge all over the world. All of the above problems, as well as the enormous
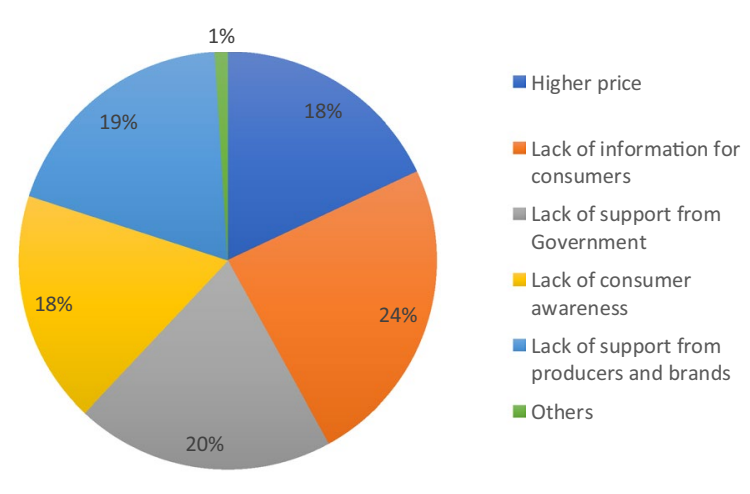

Fig. 6 Various challenges in the way of Bioplastics 


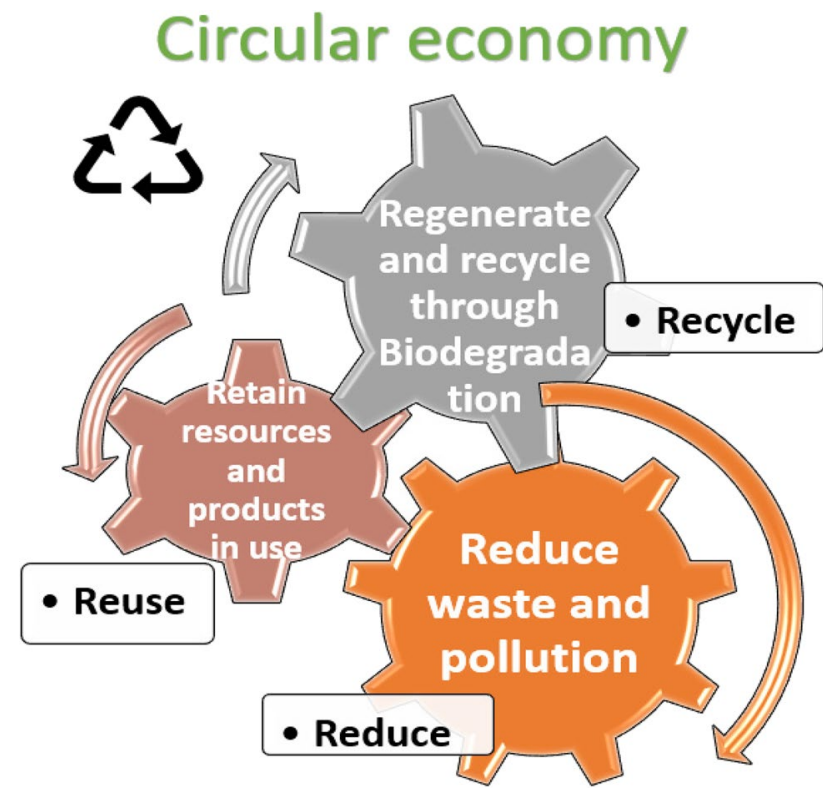

Fig. 7 Different components of circular economy

scale of COVID-19 waste generation, highlight the need for new strategies and techniques for hazardous waste during such a global pandemic. Even though COVID-waste management is still in its early stages, lessons learned from previous diseases such as AIDS, MERS-CoV, and SARS$\mathrm{CoV}-1$, as well as the creation of new and effective ways to deal with coronavirus, are being considered. As a result, it is critical to collect disparate data on coronavirus waste management when considering a circular economy with minimal waste (Teymourian et al. 2021).

\section{An account of PHA: promising biodegradable plastics}

Polyhydroxyalkanoates (PHA) are naturally derived biopolymers, which are synthesised by various microbes in granular form (Koller, 2017) as shown in Fig. 8 in the presence of carbon-rich and nitrogen-deficient medium (Surendran et al. 2020). Different bacterial strains like gram-negative bacteria, gram-positive bacteria, archaea, and photosynthetic bacteria are capable of producing PHA in both aerobic and anaerobic conditions. Approximately 150 various types of

Fig. 8 PHA accumulation in the form of granules (Image courtesy: E. Ingolić, FELMIZFE Graz)
PHA have been discovered till now (Mitra et al. 2020). Small pore size with high recycling potential, biodegradability, high volume to surface area ratio, and biocompatibility are all advantages of PHA. PHA has recently attracted attention due to a variety of beneficial properties such as ease of processing, UV resistance, and water insolubility, among others (Dwivedi et al. 2020). These beneficial properties make them viable replacement of materials like polyethylene terephthalate, polylactic acid, bio-polyamide, and other non-biodegradable materials that are employed in different sectors such as medical, agriculture, and food. Regardless of their economic promise, most PHA-based biomaterials are highly hydrophobic, have a low heat distortion temperature, and have poor gas barrier properties, particularly crystalline short chain length PHA with greater monomeric compositions of 3-hydroxybutyric acid such as poly hydroxybutyrate (PHB). As a result of these limitations, they degrade slowly (Raza et al. 2020). When compared to other bioplastics, the cost of producing PHA is much higher. As a result, these biopolymers fall short of meeting industrial demands. As a result, different approaches to improving the chemical and mechanical properties of the PHA by altering the biopolymers have been devised to resolve these shortcomings.

\section{Structure of polyhydroxyalkanoate}

A PHA molecule has monomeric units of (R)-hydroxy fatty acid (Dobrogojski et al. 2018). Different monomers are joint to each other through ester linkage (Tan et al. 2014). Each monomer consists of a side chain $\mathrm{R}$ group (alkyl group that can be either saturated or unsaturated), substituted alkyl groups, and branched alkyl groups. PHA is divided into the following three types based on the length of their structural chain:

\section{Short-chain length PHA (scl-PHA)}

They contain monomers of 3-5 carbons. For example, poly (3-hydroxybutyrate) (PHB) and poly (3-hydroxyvalerate) (PHV) as drawn in Fig. 9 are accumulated by Cupriavidus necator. Chain length is short. PHA is too rigid and brittle

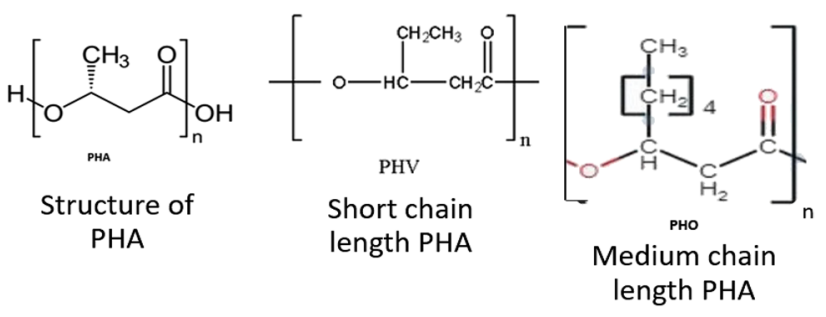

Fig. 9 Different structures of PHA molecules where ' $n$ ' accounts for degree of polymerisation 
also they lack greater mechanical properties which are necessarily needed for packaging and biomedical applications (Li et al. 2016a, b).

\section{Medium-chain length PHA (mcl-PHA)}

They contain monomeric units of 6-14 carbons. For example, poly (3-hydroxyoctanoate) (PHO) structure is given in Fig. 9 which is accumulated by Pseudomonas mendocina. These PHAs are elastomeric but have very low mechanical strength which restricts their applications in diverse sectors (Nomura et al. 2004).

\section{Long-chain length PHA}

They have monomer building blocks of 15 or more than 15 carbons. For example, poly (3-hydroxypentadecanoate) is accumulated by Pseudomonas aeruginosa.

\section{Properties of PHA}

PHA shares many of the same properties as petroleumbased polymers (Keskin et al. 2017). Insolubility in water, UV resistance, high degree of polymerisation, stiffness, biodegradability, and thermoplasticity are some of the physical properties of PHA.

\section{Applications of PHA}

PHA has diverse application ranging from agriculture, energy, biomedical to packaging sector. Different type of usage is given in different sector as described in Fig. 10 (Sharma et al. 2021). But COVID-19 has driven the high demand in packaging market and promoted production.

\section{PHA market report and COVID-19}

According to PHA Market report 2021, the packaging industry, particularly for food, beverage, and medicines, would benefit the most from bioplastics. The buyers were pushed to the retail channel due to the restaurant industry's shutdown during COVID-19. Plastics are used to pack the majority of foods sold in retail outlets. There were numerous collaborations and agreements between PHA manufacturers and the food packaging industries, indicating that this sector is growing rapidly, while on the other hand, due to a decline in oil prices in 2020, virgin plastic became less expensive than biodegradable plastics, posing a short-term market constraint. Based on the above-mentioned factors, the polyhydroxyalkanoate (PHA) market is projected to have a neutral impact in 2020 and to rise at a positive rate over the forecast period (PHA Market report 2021).

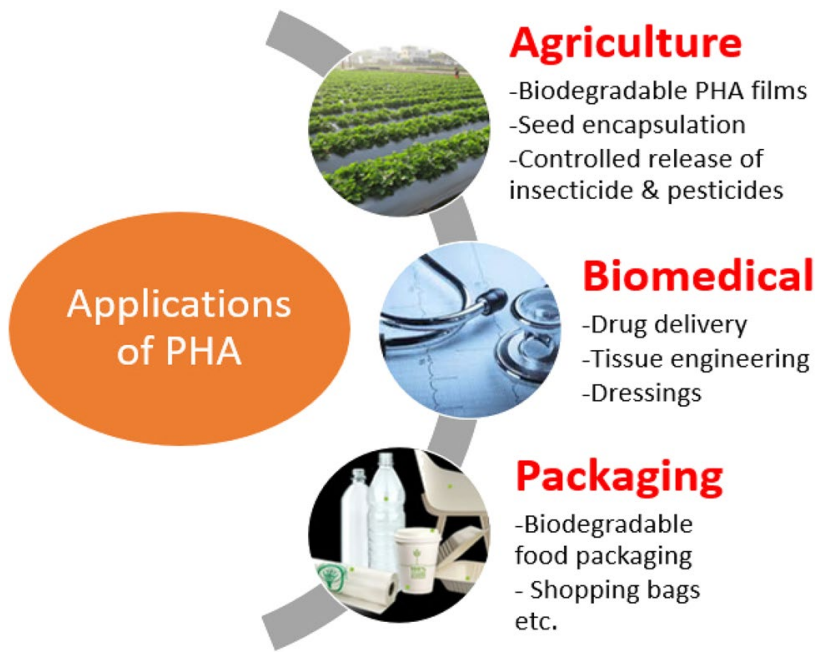

Fig. 10 Applications of PHA

PHA is used extensively in the packaging and food service sectors. PHA demand is expected to rise in this segment due to its increasing use in a variety of applications, for instance, cups, lids, food containers, and other food service items. Growing environmental problems and waste management issues are the key drivers of this section (PHA Market report 2021).

\section{Drawbacks of PHA}

PHAs are gaining a lot of attention these days because of their biodegradability, but their high production cost and need for complex substrates for processing have resulted in a decrease in their demand in various fields. These are roughly 15 times more costly than polymers derived from petroleum (Możejko-Ciesielska and Kiewisz 2016). One of the most significant limitations of commercial PHA development is maintaining the optimum bacterial growth conditions. Most of the fermentation processes do not allow optimum production of PHA granules at the end of the cultivation.

\section{Strategies for minimising PHA production cost}

\section{Cost-effective substrate}

PHA's high cost is due to the complex substrates, which account for $30-40 \%$ of overall cost. PHA can be made from inexpensive substrates like glucose, lignin, sucrose, and waste. For PHA development, new biosynthesis pathways using low-cost substrates can be created (Andler et al. 2019). The resulting recombinant could generate large amounts of PHB from glycerol by incorporating genes encoding aqua glycophorin and glycerol kinase from $E$. coli into the chromosome of Cupriavidus necator H16 (Fukui et al. 2014). 
Co-productions of PHA with alcohols, amino acids, biosurfactants, and other useful chemicals, among other things, have been published.

\section{Developing improved bacterial strains}

Another technique for lowering PHA development costs and increasing yield is to use transgenically modified bacterial strains. Consider the following scenario, C. necator is a metabolically engineered mutant strain that expresses genes encoding L-arabinose catabolic enzymes, allowing it to use $\mathrm{L}$-arabinose as a carbon substrate and accumulate high levels of PHB (Liu et al. 2016).

\section{Reduction in cost of purification}

Cell and broth separation, as well as product recovery, are all part of PHA's downstream production. Expensive centrifugation, micro-filtration, and other time-consuming processes are needed for the separation (Jiang and Chen 2016). As a result, methods for recovering PHA through an easy, reliable, and less polluting process must be developed.

\section{Future considerations and recommendations}

We may find that our dependence on plastic has raised as a lockdown or other restrictions are progressively lifted. Increased use of PPE and SUP would result from the resumption of economic activity and movement of population, resulting in a rise in waste generation. Managing the growing amount of single-use plastic waste will be a huge challenge for all governments, particularly in many developing countries. Solving the COVID-19 crisis cannot be done at the cost of addressing humanity's longer-term problem: the climate crisis (Climate Action Tracker 2020). More funds should be allocated by corporations as well as governments worldwide to teach people about the circular economy and why they should go for reuse and recycle (Sharma et al. 2020). According to research, simply presenting information through an awareness drive is unlikely to result in behaviour change. For example, media coverage and public awareness campaigns about the proper disposal of personal protective equipment (PPE) such as masks and gloves in a sealed garbage bag will address concerns about sanitation workers' safety (Prata et al. 2020). This can have an indirect effect on our actions by increasing our vulnerability to other interventions and reflecting social norms - the unwritten rules of appropriate behaviour (Huang 2016). When we become aware of a problem, we can need some assistance in moving from awareness to action. According to a new report, voice trigger action causes background change and encourages pro-environmental behaviours (Ohtomo and Ohnuma 2014).
By changing the norms, we can successfully phase out our reliance on single-use plastic goods. The more we talk about the issue and the solutions, the more companies will search out and propose alternatives, and we will be more likely to mobilise as a community (Innerself 2020).

\section{Conclusions}

While human health should take precedence, environmental health should also be considered for the greater good of the entire planet. It is not only the government's responsibility to ensure environmental safety, but also the individual's responsibility to be active and behave responsibly by selecting reusable personal protection equipment, minimising the use of disposable products, choosing environmentally friendly materials such as bioplastics, and appropriately disposing of them. If we think of reduce, reuse, and recycle, the world will become safer, the natural resources will automatically be secured, and harmful emissions will be minimised. To summarise, pandemic situations such as COVID-19 can be easily tackled with full effort and collaboration between the government and the public. Then only environmental and individual security can be easily achieved.

Author contribution Mahak Mittal: conceptualisation, resources, methodology, writing — original draft. Divya Mittal: visualisation, writingreview and editing. Neeraj K. Aggarwal: formal analysis, supervision, writing-review and editing.

Funding One of the authors Mahak Mittal acknowledged the Rashtriya Uchchatar Shiksha Abhiyan (RUSA) 2.0 for providing financial support and Kurukshetra University, Kurukshetra.

Data availability Not applicable.

\section{Declarations}

Ethics approval Not applicable.

Consent to participate Not applicable.

Consent for publication Not applicable.

Competing interests The authors declare no competing interests.

\section{References}

Abbasi SA, Khalil AB, Arslan M (2020) Extensive use of face masks during COVID-19 pandemic:(micro-) plastic pollution and potential health concerns in the Arabian Peninsula. Saudi J Biol Sci 27(12):3181-3186. https://doi.org/10.1016/j.sjbs.2020.09. 054

ADB. Managing infectious medical waste during the COVID-19 pandemic. https://www.adb.org/sites/default/files/publication/ 
578771/managing-medical-wastecovid19.pdf. 2020. (Accessed 16 March 2021)

Ampelli C, Perathoner S, Centi G (2015) CO2 utilization: an enabling element to move to a resource-and energy-efficient chemical and fuel production. Phil Trans R Soc A Math Phys Eng Sci 373(2037):20140177. https://doi.org/10.1098/rsta.2014. 0177

Anderson A, Chandralingam R, PraveenKumar TR (2021) Impact of COVID-19 pandemic on plastic surge and environmental effects. Energy Sources A Recover Utilization Environ Effects:1-7. https://doi.org/10.1080/15567036.2021.1900456

Andler R, Vivod R, Steinbchel A (2019) Synthesis of polyhydroxyalkanoates through the biodegradation of poly (cis-1, 4-isoprene) rubber. J Biosci Bioeng 127(3):360-365. https://doi.org/10. 1016/j.jbiosc.2018.08.015

Andrady AL (2011) Microplastics in the marine environment. Mar Pollut Bull 62(8):1596-1605. https://doi.org/10.1016/j.marpo lbul.2011.05.030

Auras R, Harte B, Selke S (2004) An overview of polylactides as packaging materials. Macromol Biosci 4(9):835-864. https://doi.org/ 10.1002/mabi.200400043

Beaumont NJ, Aanesen M, Austen MC, Brger T, Clark JR, Cole M, ... Wyles KJ (2019) Global ecological, social and economic impacts of marine plastic. Mar Pollut Bull 142: 189-195. https://doi.org/ 10.1016/j.marpolbul.2019.03.022

Beeching NJ, Fletcher TE, Beadsworth MB (2020) Covid-19: testing times. https://doi.org/10.1136/bmj.m1403

Bengali S (2020) The COVID-19 pandemic is unleashing a tidal wave of plastic waste. The Los Angeles Times. https://www.latimes. com/world-nation/story/2020-06-13/coronavirus-pandemic-plast ic-waste-recycling. (Accessed 17 March 2021)

Biogreen. Biogreen is India's first biotechnology company https:// www.biogreenbags.com. 2017. (Accessed 20 March 2021)

Celis JE, Espejo W, Paredes-Osses E, Contreras SA, Chiang G, Bahamonde P (2021) Plastic residues produced with confirmatory testing for COVID-19: classification, quantification, fate, and impacts on human health. Sci Total Environ 760:144167. https:// doi.org/10.1016/j.scitotenv.2020.144167

Crumbley AM, Gonzalez R (2018) Cracking economies of scale: biomanufacturing on methane-rich feedstock. In: Methane biocatalysis: paving the way to sustainability. Springer, Cham, pp 271-292. https://doi.org/10.1007/978-3-319-74866-5_17

Dietz L, Horve PF, Coil DA, Fretz M, Eisen JA, Van Den Wymelenberg K (2020) 2019 novel coronavirus (COVID-19) pandemic: built environment considerations to reduce transmission. Msystems 5(2): $\mathrm{e} 00245-20$

Dilkes-Hoffman LS, Pratt S, Lant PA, Laycock B (2019) The role of biodegradable plastic in solving plastic solid waste accumulation. In: Plastics to energy. William Andrew Publishing, pp 469-505. https://doi.org/10.1016/B978-0-12-813140-4.00019-4

Dobrogojski J, Spychalski M, Luciński R, Borek S (2018) Transgenic plants as a source of polyhydroxyalkanoates. Acta Physiol Plant 40(9):1-17. https://doi.org/10.1007/s11738-018-2742-4

Dogu O, Pelucchi M, Van de Vijver R, Van Steenberge PH, D'hooge DR, Cuoci A, ... Van Geem KM (2021) The chemistry of chemical recycling of solid plastic waste via pyrolysis and gasification: state-of-the-art, challenges, and future directions. Progress in Energy and Combustion Science 84: 100901. https://doi.org/ 10.1016/j.pecs.2020.100901

Drre P, Eikmanns BJ (2015) C1-carbon sources for chemical and fuel production by microbial gas fermentation. Curr Opin Biotechnol 35:63-72. https://doi.org/10.1016/j.copbio.2015.03.008

Dwivedi R, Pandey R, Kumar S, Mehrotra D (2020) Poly hydroxyalkanoates (PHA): role in bone scaffolds. Journal of Oral Biology and Craniofacial Research 10(1):389-392. https://doi.org/10. 1016/j.jobcr.2019.10.004
Eriksen M, Lebreton LC, Carson HS, Thiel M, Moore C J, Borerro JC, ... Reisser J (2014) Plastic pollution in the world's oceans: more than 5 trillion plastic pieces weighing over 250,000 tons afloat at sea. PloS one 9(12): e111913. https://doi.org/10.1371/ journal.pone. 0111913

European bioplastics, nova institute (2020), www.european-bioplastics. org/market. (Accessed 15 March 2021)

European Commission- Single use plastics: new EU rules to reduce marine litter, 28 May 2018 https://ec.europa.eu/commission/ presscorner/detail/en/IP_18_3927. (Accessed 16 March 2021)

European Environment Agency. Published on 22 June 2021 https:// www.eea.europa.eu/highlights/covid19-in-europe-increasedpollution

Fadare OO, Okoffo ED (2020) Covid-19 face masks: a potential source of microplastic fibers in the environment. Sci Total Environ 737:140279. https://doi.org/10.1016/j.scitotenv.2020.140279

Fast Company- By Kristian Toussaint, 2 May 2021 https://www.fastc ompany.com/90601079/the-covid-19-vaccine-rollout-is-goingto-create-a-massive-waste-management-problem. (Accessed 13 May 2021)

Fukui T, Mukoyama M, Orita I, Nakamura S (2014) Enhancement of glycerol utilization ability of Ralstonia eutropha H16 for production of polyhydroxyalkanoates. Appl Microbiol Biotechnol 98(17):7559-7568. https://doi.org/10.1007/s00253-014-5831-3

Ghosh S, Das S, Mondal R, Abdullah S, Sultana S, Singh S, ... Behl $\mathrm{T}$ (2021) A review on the effect of COVID-19 in type 2 asthma and its management. Int Immunopharmacol 91: 107309. https:// doi.org/10.1016/j.intimp.2020.107309

Hahladakis JN, Velis CA, Weber R, Iacovidou E, Purnell P (2018) An overview of chemical additives present in plastics: migration, release, fate and environmental impact during their use, disposal and recycling. J Hazard Mater 344:179-199. https://doi.org/10. 1016/j.jhazmat.2017.10.014

Hahladakis JN, Iacovidou E, Gerassimidou S (2020) Plastic waste in a circular economy. In: Plastic waste and recycling. Academic Press, pp 481-512 https://doi.org/10.1016/B978-0-12-817880-5. 00019-0

Haider TP, Vlker C, Kramm J, Landfester K, Wurm FR (2019) Plastics of the future? The impact of biodegradable polymers on the environment and on society. Angew Chem Int Ed 58(1):50-62. https://doi.org/10.1002/anie.201805766

Huang H (2016) Media use, environmental beliefs, self-efficacy, and pro-environmental behavior. J Bus Res 69(6):2206-2212. https:// doi.org/10.1016/j.jbusres.2015.12.031

India Bio plastics Market - Industry Analysis and Forecast (20192026) by Product and by Application. https://www.maximizema rketresearch.com/market-report/india-bio-plastics-market/ 21457/. (Accessed 17 April 2021)

InnerSelf BK (2020) How to break up with plastics using Behavioural science

Ivanov V, Christopher L (2016) Biorefinery-derived bioplastics as promising low-embodied energy building materials. In: Nano and Biotech Based Materials for Energy Building Efficiency. Springer, Cham, pp 375-389. https://doi.org/10.1007/978-3319-27505-5_13

Jiang XR, Chen GQ (2016) Morphology engineering of bacteria for bio-production. Biotechnol Adv 34(4):435-440. https://doi.org/ 10.1016/j.biotechadv.2015.12.007

Kalita K (2019) India's first biodegradable plastic developed by IITGuwahati. https://timesofindia.indiatimes.com/city/guwahati/ indias-first-biodegradable-plastic-developedby-iit-guwahati/artic leshow/68133589.cms. Accessed 15 May 2021

Keskin G, Kızıl G, Bechelany M, Pochat-Bohatier C, Öner M (2017) Potential of polyhydroxyalkanoate (PHA) polymers family as substitutes of petroleum based polymers for packaging applications and solutions brought by their composites to form barrier 
materials. Pure Appl Chem 89(12). https://doi.org/10.1515/ pac-2017-0401

Khoo KS, Ho LY, Lim HR, Leong HY, Chew KW (2021) Plastic waste associated with the COVID-19 pandemic: crisis or Opportunity? J Hazard Mater:126108. https://doi.org/10. 1016/j.jhazmat.2021.126108

Kleme JJ, Fan YV, Jiang P (2020) Plastics: friends or foes. The circularity and plastic waste footprint. Energy Sources A Recover Utilization Environ Effects. https://doi.org/10.1080/15567036. 2020.1801906

Kleme JJ, Van Fan Y, Tan RR, Jiang P (2020b) Minimising the present and future plastic waste, energy and environmental footprints related to COVID-19. Renew Sustain Energy Rev 127:109883. https://doi.org/10.1016/j.rser.2020.109883

Koller M (2017) Production of polyhydroxyalkanoate (PHA) biopolyesters by extremophiles. MOJ Polymer Science 1(2):1-19

Leal Filho W, Salvia AL, Bonoli A, Saari UA, Voronova V, Klõga M, ... Barbir J (2021) An assessment of attitudes towards plastics and bioplastics in Europe. Sci Total Environ 755: 142732. https://doi.org/10.1016/j.scitotenv.2020.142732

Li WC, Tse HF, Fok L (2016a) Plastic waste in the marine environment: a review of sources, occurrence and effects [J]. Sci Total Environ:566-567. https://doi.org/10.1016/j.scitotenv.2016.05. 084

Li Q, Guan X, Wu P, Wang X, Zhou L, Tong Y, ... Feng Z (2020) Early transmission dynamics in Wuhan, China, of novel coronavirus-infected pneumonia. N Engl J Med. https://doi.org/10. 1056/NEJMoa2001316

Li Z, Yang J, Loh XJ (2016b) Polyhydroxyalkanoates: opening doors for a sustainable future. NPG Asia Mater 8(4):e265-e265. https://doi.org/10.1038/am.2016.48

Liebsch T (2020) The rise of the face mask: what's the environmental impact of 17 million N95 masks

Liew KC, Khor LK (2015) Effect of different ratios of bioplastic to newspaper pulp fibres on the weight loss of bioplastic pot. J King Saud Univ Eng Sci 27(2):137-141. https://doi.org/10. 1016/j.jksues.2013.08.001

Liu CC, Zhang LL, An J, Chen B, Yang H (2016) Recent strategies for efficient production of polyhydroxyalkanoates by microorganisms. Lett Appl Microbiol 62(1):9-15. https://doi.org/ 10.1111/lam.12511

Lunt J (1998) Large-scale production, properties and commercial applications of polylactic acid polymers. Polym Degrad Stab 59(1-3):145-152. https://doi.org/10.1016/S0141-3910(97) 00148-1

Mackenzie JS, Smith DW (2020) COVID-19: a novel zoonotic disease caused by a coronavirus from China: what we know and what we don't. Microbiol Aust 41(1):45-50. https://doi.org/10.1071/ MA20013

Manigandan S, Wu MT, Ponnusamy VK, Raghavendra VB, Pugazhendhi A, Brindhadevi K (2020) A systematic review on recent trends in transmission, diagnosis, prevention and imaging features of COVID-19. Process Biochem. https://doi.org/10.1016/j. procbio.2020.08.016

Mitra R, Xu T, Xiang H, Han J (2020) Current developments on polyhydroxyalkanoates synthesis by using halophiles as a promising cell factory. Microb Cell Fact 19:1-30. https://doi.org/10.1186/ s12934-020-01342-z

Moens EK, De Smit K, Marien YW, Trigilio AD, Van Steenberge PH, Van Geem KM, ... D'hooge DR (2020) Progress in reaction mechanisms and reactor technologies for thermochemical recycling of poly (methyl methacrylate). Polymers 12(8): 1667. https://doi.org/10.3390/polym12081667

Możejko-Ciesielska J, Kiewisz R (2016) Bacterial polyhydroxyalkanoates: still fabulous? Microbiol Res 192:271-282. https:// doi.org/10.1016/j.micres.2016.07.010
Nagu P, Parashar A, Behl T, Mehta V (2021) CNS implications of COVID-19: a comprehensive review. Rev Neurosci 32(2):219234. https://doi.org/10.1515/revneuro-2020-0070

Naser AZ, Deiab I, Darras BM (2021) Poly (lactic acid) (PLA) and polyhydroxyalkanoates (PHAs), green alternatives to petroleum-based plastics: a review. RSC Adv 11(28):17151-17196. https://doi.org/10.1039/D1RA02390J

Negrut N, Codrean A, Hodisan I, Bungau S, Tit DM, Marin R ... Nistor-Cseppento DC (2021) Efficiency of antiviral treatment in COVID-19. Exp Ther Med 21: 648. https://doi.org/10.3892/ etm.2021.10080

Nomura CT, Tanaka T, Gan Z, Kuwabara K, Abe H, Takase K, ... Doi Y (2004) Effective enhancement of short-chainlength-medium-chain-length polyhydroxyalkanoate copolymer production by coexpression of genetically engineered 3-ketoacyl-acyl-carrier-protein synthase III (f abH) and polyhydroxyalkanoate synthesis genes. Biomacromolecules 5(4), 1457-1464. https://doi.org/10.1021/bm049959v

North E, Halden R (2013) Plastics and environmental health: the road ahead. Rev Environ Health 28(1):1-8. https://doi.org/10. 1515/reveh-2012-0030

Ohtomo S, Ohnuma S (2014) Psychological interventional approach for reduce resource consumption: reducing plastic bag usage at supermarkets. Resour Conserv Recycl 84:57-65. https://doi. org/10.1016/j.resconrec.2013.12.014

Pan D, Su F, Liu C, Guo Z (2020) Research progress for plastic waste management and manufacture of value-added products. Adv Compos Hybrid Mater:1-19. https://doi.org/10.1007/ s42114-020-00190-0

Payne J, McKeown P, Jones MD (2019) A circular economy approach to plastic waste. Polym Degrad Stab 165:170-181. https://doi. org/10.1016/j.polymdegradstab.2019.05.014

Peelman N, Ragaert P, De Meulenaer B, Adons D, Peeters R, Cardon L, ... Devlieghere F (2013) Application of bioplastics for food packaging. Trends Food Sci Technol 32(2): 128-141. https:// doi.org/10.1016/j.tifs.2013.06.003

Phadke R, dos Santos Costa AC, Dapke K, Ghosh S, Ahmad S, Tsagkaris C, ... Ahmad S (2021) Eco-friendly vaccination: tackling an unforeseen adverse effect. J Clim Chang Health 1: 100005. https://doi.org/10.1016/j.joclim.2021.100005

Philp JC, Bartsev A, Ritchie RJ, Baucher MA, Guy K (2013) Bioplastics science from a policy vantage point. New Biotechnol 30(6):635-646. https://doi.org/10.1016/j.nbt.2012.11.021

Picheta R. Coronavirus is causing a flurry of plastic waste. Campaigners fear it may be permanent. https://edition.cnn.com/ 2020/05/04/world/coronavirus-plastic-waste-pollution-intl/ index.html. 2020. (Accessed 16 March 2021)

Polyhydoxyalkanoate (PHA) Market. Published on Feb 2021, Report Code: CH 1610 https://www.marketsandmarkets.com/MarketReports/pha-market-395.html (Accessed 13 May 2021)

Potrykus M, Redko V, Głowacka K, Piotrowicz-Cieślak A, Szarlej P, Janik H, Wolska L (2021) Polypropylene structure alterations after 5 years of natural degradation in a waste landfill. Sci Total Environ 758:143649. https://doi.org/10.1016/j.scito tenv.2020.143649

Prata JC, Silva AL, Walker TR, Duarte AC, Rocha-Santos T (2020) COVID-19 pandemic repercussions on the use and management of plastics. Environ Sci Technol 54(13):7760-7765. https://doi.org/10.1021/acs.est.0c02178

Raza ZA, Khalil S, Abid S (2020) Recent progress in development and chemical modification of poly (hydroxybutyrate) based blends for potential medical applications. Int J Biol Macromol. https://doi.org/10.1016/j.ijbiomac.2020.05.114

Reuters. Discarded coronavirus masks clutter Hong Kong's beaches, trails. https://www.reuters.com/article/us-health-coron 
avirus-hongkong-environmeidUSKB N20Z0PP. 2020. (Accessed 25 April 2021)

Rhodes CJ (2018) Plastic pollution and potential solutions. Sci Prog 101(3):207-260. https://doi.org/10.3184/003685018X15294 876706211

Saxon DJ, Luke AM, Sajjad H, Tolman WB, Reineke TM (2020) Nextgeneration polymers: isosorbide as a renewable alternative. Prog Polym Sci 101:101196. https://doi.org/10.1016/j.progpolymsci. 2019.101196

Scaraboto D, Joubert AM, Gonzalez-Arcos C (2019) Using lots of plastic packaging during the coronavirus crisis? You're not alone. The Conversation 668, 1077-1093. https://theconversation.com/ using-lots-of-plastic-packaging-during-the-coronavirus-crisisyoure-not-alone-135553. (Accessed 22 April 2021)

Selvaranjan K, Navaratnam S, Rajeev P, Ravintherakumaran N (2021) Environmental challenges induced by extensive use of face masks during COVID-19: a review and potential solutions. Environ Challenges: 100039. https://doi.org/10.1016/j.envc.2021.100039

Shafqat A, Tahir A, Mahmood A, Tabinda AB, Yasar A, Pugazhendhi A (2020) A review on environmental significance carbon foot prints of starch based bio-plastic: a substitute of conventional plastics. Biocatal Agric Biotechnol 27:101540. https://doi.org/ 10.1016/j.bcab.2020.101540

Sharma HB, Vanapalli KR, Cheela VS, Ranjan VP, Jaglan AK, Dubey $\mathrm{B}, \ldots$ Bhattacharya J (2020) Challenges, opportunities, and innovations for effective solid waste management during and post COVID-19 pandemic. Resour Conserv Recycl 162: 105052. https://doi.org/10.1016/j.resconrec.2020.105052

Sharma V, Sehgal R, Gupta R (2021) Polyhydroxyalkanoate (PHA): properties and modifications. Polymer 212:123161. https://doi. org/10.1016/j.polymer.2020.123161

Shen L, Haufe J, Patel MK (2009) Product overview and market projection of emerging bio-based plastics PRO-BIP 2009. Report for European polysaccharide network of excellence (EPNOE) and European bioplastics: 243

Silva ALP, Prata JC, Walker TR, Campos D, Duarte AC, Soares AM, ... Rocha-Santos T (2020a) Rethinking and optimising plastic waste management under COVID-19 pandemic: policy solutions based on redesign and reduction of single-use plastics and personal protective equipment. Sci Total Environ 742: 140565. https:// doi.org/10.1016/j.scitotenv.2020.140565

Silva ALP, Prata JC, Walker TR, Duarte AC, Ouyang W, Barcel D, Rocha-Santos T (2020b) Increased plastic pollution due to COVID-19 pandemic: challenges and recommendations. Chem Eng J: 126683. https://doi.org/10.1016/j.cej.2020.126683

Sin LT, Rahmat AR, Rahman WA, Ebnesajjad S (2013) Handbook of biopolymers and biodegradable plastics

Sinan M (2020) Bioplastics for sustainable development: general scenario in India. Curr World Environ 15(1):24

Sinclair RG (1996) The case for polylactic acid as a commodity packaging plastic. J Macromol Sci Part A Pure Appl Chem 33(5):585-597. https://doi.org/10.1080/10601329608010880

Singh N, Tang Y, Zhang Z, Zheng C (2020) COVID-19 waste management: effective and successful measures in Wuhan, China. Resour Conserv Recycl 163:105071. https://doi.org/10.1016/j. resconrec.2020.105071

Singh SH (2020) Lockdown helps bring back plastic bags. The Hindu. https://www.thehindu.com/news/national/telangana/lockdownhelps-bring-back-plasticbags/article31381638.ece (Accessed 17 March 2021)

Staub C (2020) Country lockdowns bring 'unprecedented implications.' Resource recycling.https://resource-recycling.com/plast ics/2020/04/01/country-lockdownsbring-unprecedented-impli cations/ (Accessed 22 April 2021)

Surendran A, Lakshmanan M, Chee JY, Sulaiman AM, Van Thuoc D, Sudesh K (2020) Can polyhydroxyalkanoates be produced efficiently from waste plant and animal oils? Front Bioeng Biotechnol 8. https://doi.org/10.3389/fbioe.2020.00169

Tan GYA, Chen CL, Li L, Ge L, Wang L, Razaad IMN, ... Wang JY (2014) Start a research on biopolymer polyhydroxyalkanoate (PHA): a review. Polymers 6(3): 706-754. https://doi.org/10. 3390/polym6030706

Tang YW, Schmitz JE, Persing DH, Stratton CW (2020) Laboratory diagnosis of COVID-19: current issues and challenges. J Clin Microbiol 58(6). https://doi.org/10.1128/JCM.00512-20

Tedeschi G, Guzman-Puyol S, Ceseracciu L, Paul UC, Picone P, Di Carlo M, ... Heredia-Guerrero JA (2020) Multifunctional bioplastics inspired by wood composition: effect of hydrolyzed lignin addition to xylan-cellulose matrices. Biomacromolecules 21(2): 910-920. https://doi.org/10.1021/acs.biomac. 9b01569

Tenenbaum L (2020) The amount of plastic waste is surging because of the coronavirus pandemic. Forbes. https://www.forbes.com/ sites/lauratenenbaum/2020/04/25/plastic-waste-during-the-timeof-covid-19/?sh=945a7477e484 (Accessed 20 April 2021)

Teymourian T, Teymoorian T, Kowsari E, Ramakrishna S (2021) Challenges, strategies, and recommendations for the huge surge in plastic and medical waste during the global COVID-19 pandemic with circular economy approach. Mater Circ Econ 3(1):1-14. https://doi.org/10.1007/s42824-021-00020-8

The Print- By Himani Chandna, 10 April 2021 https://theprint.in/ health/this-is-how-india-is-disposing-of-its-lakhs-lakhs-ofcovid-vaccine-syringes/636751/ (Accessed 13 May 2021)

Tobas A (2020) Evaluation of the lockdowns for the SARS-CoV-2 epidemic in Italy and Spain after one month follow up. Sci Total Environ 725:138539. https://doi.org/10.1016/j.scitotenv.2020. 138539

Tracker CA (2020) A government roadmap for addressing the climate and post COVID-19 economic crises. CAT (Climate Action Tracker). URL: https://climateactiontracker.org/publications/ addressing-theclimate-and-post-covid-19-economic-crises/. (Accessed 10 May 2021)

Tsang YF, Kumar V, Samadar P, Yang Y, Lee J, Ok YS, ... Jeon YJ (2019) Production of bioplastic through food waste valorization. Environment international 127: 625-644. https://doi.org/ 10.1016/j.envint.2019.03.076

Ummalyma SB, Sahoo D, Pandey A (2020) Microalgal biorefineries for industrial products. In Microalgae Cultivation for Biofuels Production. Academic Press, pp 187-195. https://doi.org/10. 1016/B978-0-12-817536-1.00012-6

Vert M, Schwarch G, Coudane J (1995) Present and future of PLA polymers. J Macromol Sci Part A Pure Appl Chem 32(4):787-796. https://doi.org/10.1080/10601329508010289

WHO, World Health Organization Director-General's opening remarks at the media briefing on COVID-19 - 11 March. 2020b https:// www.who.int/dg/speeches/detail/who-director-general-s-openi ng-remarks-at-the-media-briefing-oncovid-19-11-march-2020 (Accessed 20 April 2021).

WHO. Shortage of personal protective equipment endangering health workers worldwide, 3 March 2020a https://www.who.int/newsroom/detail/03-03-2020-shortage-of-personal-protectiveequip ment-endangering-health-workers-worldwide. 2020 (Accessed 20 April 2021)

Wilson DC, Rodic L, Modak P, Soos R, Carpintero A, Velis K et al (2015) Global waste management outlook. UNEP

Wipatayotin A. Covid-19 pushes plastic waste rise. https://www.bangk okpost.com/thailand/general/1906295/covid-19-pushes-plasticwaste-rise. 2020. (Accessed 15 March 2021)

World Health Organization. (2020) Water, sanitation, hygiene, and waste management for the COVID-19 virus: interim guidance, 23 April 2020c (No. WHO/2019-nCoV/IPC_WASH/2020.3). World Health Organization. (Accessed 10 April 2021) 
Wright SL, Kelly FJ (2017) Plastic and human health: a micro issue? Environ Sci Technol 51(12):6634-6647. https://doi.org/10.1021/ acs.est.7b00423

Wu Y, Xu X, Chen Z, Duan J, Hashimoto K, Yang L, ... Yang C (2020) Nervous system involvement after infection with COVID-19 and other coronaviruses. Brain Behav Immun 87: 18-22. https://doi. org/10.1016/j.bbi.2020.03.031

Xiang PXXM, Xu XM, Gao LL, Wang HZ, Xiong HF, Li RH (2020a) First case of 2019 novel coronavirus disease with encephalitis. ChinaXiv 202003:00015

Xiang Y, Song Q, Gu W (2020b) Decontamination of surgical face masks and N95 respirators by dry heat pasteurization for one hour at $70 \mathrm{C}$. Am J Infect Control 48(8):880-882. https://doi. org/10.1016/j.ajic.2020.05.026

Zhang W, Alvarez-Gaitan JP, Dastyar W, Saint CP, Zhao M, Short MD (2018) Value-added products derived from waste activated sludge: a biorefinery perspective. Water 10(5):545. https://doi. org/10.3390/w10050545

Publisher's note Springer Nature remains neutral with regard to jurisdictional claims in published maps and institutional affiliations. 